Treatment success was defined as $>50 \%$ reduction in episodes of faecal incontinence with PTNS when compared to baseline symptoms.

Results Twenty two patients underwent PTNS over the above period (M: F; 21:1). Sixteen of the 22 patients showed a $>50 \%$ improvement in their weekly FI episodes. Clinical outcome of percutaneous PTNS was not affected by age, body mass index or duration of symptoms.

The presence of a combined motor response (evidenced by fanning out of all the toes) and a sensory response (evidenced by a tingling sensation over the plantar aspect of the foot) on PTNS was better associated with a successful outcome than the presence of either a motor or a sensory response alone ( $p$ $=0.008)$. A lower stimulation voltage to obtain stimulation response was not associated with improved outcome ( $\mathrm{p}=$ 0.066). Evidence of anal sphincter trauma was not associated with a greater risk of failure $(p=0.073)$.

Over a median follow-up of 4 months (range 3-6 months) there was no difference in short-term outcome between patients with external anal sphincter (EAS) defects and patients with intact anal sphincter muscles.

Conclusion A combined motor and sensory response of percutaneous PTNS has a positive impact on treatment outcome.

Competing interests None.

Keywords Percutaneous tibial nerve stimulation, predictive factors.

\title{
REFERENCES
}

1. Govaert B, et al. A prospective multicentre study to investigate percutaneous tibial nerve stimulation for the treatment of faecal incontinence. Colorectal Dis 2010;12:1236-41.

2. de la Portilla F, et al. Evaluation of the use of posterior tibial nerve stimulation for the treatment of fecal incontinence: preliminary results of a prospective study. Dis Colon Rectum 2009;52:1427-33.

\section{PWE-070 PREDICTIVE FACTORS FOR PERCUTANEOUS TIBIAL NERVE STIMULATION FOR FAECAL INCONTINENCE}

doi:10.1136/gut.2011.239301.333

A George, ${ }_{1,2, *}$ A Panarese, ${ }^{2}$ S Sala, ${ }^{2}$ K Kalmar, ${ }^{1}$ K Kokopoulis, ${ }^{2}$ R J Nicholls, ${ }^{2}$ C J Vaizey ${ }^{1}$ Physiology, St Mark's Hospital, London, UK; ${ }^{2}$ Colorectal Surgery, St Mark's Hospital, London, UK

Introduction Though studies ${ }^{12}$ on percutaneous tibial nerve stimulation (PTNS) show it to be a safe and effective treatment for faecal incontinence (FI), there is little information regarding the predictive factors for successful PTNS.

This study aimed to identify the possible predictive factors for successful PTNS for FI.

Methods A cohort analysis was performed to identify potential predictive factors in patients who underwent percutaneous PTNS at a single institution over a 1 year period (November 2009 to November 2010).

Patients were given twice weekly 30 -min sessions of PTNS for 6 weeks followed by a further top-up session at 1 month post treatment. 